\title{
Androgen Receptor Regulates the Proliferation of Stretched Myoblasts and Its Mechanisms: IGF-1R- mediated p38 and ERK1/2 Pathways
}

\section{Shaoting Fu}

Shanghai University of Sport https://orcid.org/0000-0001-7888-7762

Xiaojing Lin

Shanghai University of Sport

Lijun Yin

Shanghai University of Sport

Xiaohui Wang ( $\square$ wangpan96@126.com)

Shanghai University of Sport, Shanghai

\section{Research}

Keywords: AR, stretch, proliferation, IGF-1R, p38, ERK1/2

Posted Date: December 28th, 2020

DOI: https://doi.org/10.21203/rs.3.rs-130571/v1

License: (c) (i) This work is licensed under a Creative Commons Attribution 4.0 International License. Read Full License 


\section{Abstract}

\section{Background}

Our previous study has indicated that in $\mathrm{C} 2 \mathrm{C} 12$ myoblasts androgen receptor (AR) plays a crucial role in 15\% stretch-induced proliferation through insulin-like growth factor (IGF-1)-modulated PI3K/Akt, p38 and ERK1/2 pathways. In this study we further explored AR's effects on $15 \%$ and $20 \%$ stretches-modulated myoblasts proliferation and involved pathways in L6 (no detectable AR) and C2C12 (abundant AR) myoblasts.

\section{Methods}

The proliferation and the above indicators were compared between stretched $\mathrm{L} 6$ and $\mathrm{C} 2 \mathrm{C} 12$ myoblasts by CCK8, ELISA and Western blot, then were detected again in stretched L6 myoblasts after transfection with AR overexpression plasmid utilizing LipoPlus ${ }^{T M} 2000$ reagent or treatment with different concentrations $(200,500,1000 \mathrm{ng} / \mathrm{ml})$ IGF-1 recombinant polypeptide.

Results

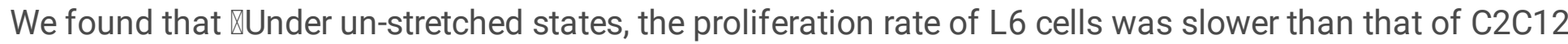
cells, and the proliferation of $\mathrm{C} 2 \mathrm{C} 12$ cells was repressed by AR knockdown using siRNA interference, while L6 myoblasts proliferation was promoted by overexpression AR. \The proliferation rate as well as the activities of $\mathrm{p} 38$ and ERK $1 / 2$ increased by $15 \%$ stretch were much lower in L6 than that in C2C12 cells; AR overexpression enhanced the proliferation of $15 \%$ stretched L6 cells accompanied with increased activities of p38 and ERK1/2; $220 \%$ stretch decreased the proliferation and activity of p38 in L6 more than that in $\mathrm{C} 2 \mathrm{C} 12$ myoblasts; overexpression of AR totally reversed the anti-proliferation of $20 \%$ stretch and significantly enhanced p38 activity in L6 myoblasts; $\$ In L6 myoblasts, overexpression AR increased IGF-1R expression despite no detectable IGF-1 was secreted; and recombinant IGF-1 increased not only the proliferation, but also the protein level of IGF-1R and activities of p38 and ERK1/2 in a dosedependent manner in $15 \%$ stretched L6 myoblasts.

\section{Conclusions}

AR fulfilled 15\% stretch-induced pro-proliferation of myoblasts by activating IGF-1R-p38 and ERK1/2 pathways, while $20 \%$ stretch-induced anti-proliferation was mediated by inhibiting AR-IGF-1R-p38 pathway. This study is beneficial to understand in depth the role and mechanisms of AR on appropriate exercise increases while excessive exercise decreases muscle mass.

\section{Background}

Testosterone is widely reported to affect muscle mass, with high level testosterone promoting whereas low level declining muscle mass, mainly via the mediation of androgen receptor (AR) [1, 2]. Decrements in serum testosterone or muscle AR during aging are associated with muscle loss [3], and general or muscle- 
specific AR deletion leads to the decline in muscle mass and strength [4-6]. Selective androgen receptor modulators (SARMs) rather than large dose of androgens are employed to increase muscle mass and strength, as androgen-induced severe adverse effects on cardiovascular system, prostate hyperplasia and so on [7-9]. In fact, not only in sedentary states, but also in acute or chronic exercise conditions, elevated AR content in skeletal muscle is closely associated with exercise-induced muscle hypertrophy and strength gain [10], and AR blockade or myofiber-specific AR deletion attenuates exercise-induced increases in muscle mass and strength $[11,12]$. Our previous work also indicated that in both resistance training and endurance training, AR plays a crucial role in training-induced muscle hypertrophy of rats using AR specific antagonist flutamide [13]. In addition, overtraining reduces the level of AR, which may be related to overtraining-induced decline in muscle mass [14].

In skeletal muscle, AR is predominantly expressed in satellite cells (skeletal muscle-derived stem cells) and myonuclei, therefore satellite cells are considered as direct target of androgens. Androgen/AR's roles in promoting the proliferation of satellite cells or myoblasts have been well demonstrated in sedentary state in vivo [15] and under un-stretched condition in vitro [16]. Our previous study indicates that in C2C12 myoblasts subjected to $15 \%$ and $20 \%$ cyclic mechanical stretches, the levels of AR were increased and decreased respectively, accompanied with pro-proliferation and anti-proliferation respectively, and AR antagonist flutamide reversed the pro-proliferation of $15 \%$ stretch on $\mathrm{C} 2 \mathrm{C} 12$ myoblasts [17], indicating the important effects of AR on stretches-modulated myoblast proliferation. But the AR's roles in exercisemodulated muscle mass or myoblasts proliferation need to be demonstrated and the molecular mechanisms require to be clarified. Totally different from C2C12 myoblasts which express AR, rat-derived L6 has no detectable AR at transcription and translation levels [18]. So the discrepancy between L6 and $\mathrm{C} 2 \mathrm{C} 12$ cells in proliferation under different stretches, and overexpression AR in L6 myoblasts as well as inhibition of AR and its downstream molecules could provide evidences for AR's role and its mechanisms.

Insulin-like growth factor (IGF-1) is an important regulator in muscle mass and strength through promoting the proliferation of satellite cells or myoblasts, increasing protein synthesis and decreasing protein degradation. It has been demonstrated that exogenous IGF-1 could significantly induce the proliferation of myoblasts in vivo and in vitro in a dose-dependent manner [19]. IGF-1 acts via binding to IGF-1 receptor (IGF-1R), and the proliferation of myoblasts is inhibited in muscle-specific IGF-1R knockout mice [20]. Upon IGF-1 binding to IGF-1R, two major signal pathways are activated: phosphoinositide 3kinases (PI3K)/Akt (also known as protein kinase B) and mitogen-activated protein kinase (MAPK) pathways including p38 and extracellular signal-regulated kinases 1 and 2 (ERK1/2) [17]. Studies in primary satellite cells or myoblast cell lines demonstrate that the stimulatory effect of IGF-1 on proliferation is mediated by PI3K/Akt and MAPKs (p38 and ERK1/2) pathways, for specific inhibitors of PI3K (LY294002), Akt (KP372-1) and ERK1/2 (PD98059) attenuate the pro-proliferation of IGF-1, respectively $[19,21]$. In fact, not only in un-stretched myoblasts, our previous work also found that in $15 \%$ mechanical stretched C2C12 myoblasts, the pro-proliferative effect of IGF-1 was realized via activating $\mathrm{PI}$ IK/Akt as well as p38 and ERK1/2 signal pathways [17]. However, whether the IGF-1/IGF-1R mediated $\mathrm{PI} 3 \mathrm{~K} / \mathrm{Akt}$, p38 and ERK1/2 signal pathways were involved in 20\% stretch-induced anti-proliferation remains unclear. 
For the relationship between AR and IGF-1/IGF-1R, numerous evidence indicate the crosstalk between androgen/AR and IGF-1/IGF-1R. Firstly, IGF-1/IGF-1R are the target genes of AR, and AR's effects in modulating myoblasts proliferation and muscle hypertrophy are mainly mediated by IGF-1/IGF-1R, because androgen response elements (AREs) exist in IGF-1 promoter and androgen/AR agonist-induced enhancements in satellite cells activation and muscle regeneration are associated with the increase of IGF-1 [22]; in addition, testosterone's effect on levator ani muscle hypertrophy and androgen/AR's role in promoting the proliferation of human skeletal muscle cells are both blocked by inhibiting IGF-1R [23]. Secondly, in turn, AR's level and activity could be elevated by IGF-1 in time- and dose-dependent manners in differentiating $\mathrm{C} 2 \mathrm{C} 12$ cells $[24,25]$.

Therefore, the present study firstly compared the discrepancy between L6 and C2C12 myoblasts subjected to $15 \%$ and $20 \%$ stretches in proliferation, levels of IGF-1 and IGF-1R, and activities of PI3K/Akt, p38 and ERK1/2, then measured the above indicators in L6 myoblasts again after transfection with AR overexpression plasmid or treatment with IGF-1 recombinant polypeptide, for demonstrating the roles of AR in stretches-regulated proliferation of myoblasts and further exploring the possible mechanisms: IGF-1 mediated alterations in the activations of PI3K/Akt and MAPKs (p38 and ERK1/2)?

\section{Methods}

\section{Methods}

\section{Cell culture}

Rat L6 myoblasts and mouse C2C12 myoblasts were purchased from Chinese Academy of Sciences Cell Bank. Cells were cultured in high-glucose Dulbecco's modified Eagle medium (DMEM) (Gibco, USA) supplemented with $10 \%$ fetal bovine serum (FBS) (Gibco, USA) as well as $100 \mathrm{U} / \mathrm{ml}$ penicillin and $100 \mu \mathrm{g} / \mathrm{ml}$ streptomycin (Gibco, USA), and maintained in 5\% CO2 $/ 95 \%$ air atmosphere at $37{ }^{\circ} \mathrm{C}$. All cells used in the experiments were at low passages (from passage 3 to passage 8 ).

\section{Plasmid construction and cell transfection}

Before transfection, high-quality plasmid DNA must be prepared. Firstly, full-length AR CDNA was amplified by specific primers (Forward:5'- CTTGGTACCGAGCTCGGATCCGCCACCATGGAGGTGCAGTTAG GGC-3' and

Reverse: 5'- TGCTGGATATCTGCAGAATTCTCCACTGTGTGTGGAAATAGA TGGG-3') designed using Primer 5.0 software. Then the PCR products were purified and digested by restriction enzymes EcoRI and BamHI (New England Biolabs, USA) at $37^{\circ} \mathrm{C}$ for $4 \mathrm{~h}$, and the digested DNA fragments were joined with linearized pcDNA3.1 vector (+) (Invitrogen, USA) by T4 DNA ligase at $4{ }^{\circ} \mathrm{C}$ overnight. Finally, the recombinant plasmids were transformed and expanded in TOP 10 Chemically Competent E.colicells, and isolated by HighPure Maxi plasmid kit (Tiangen Biotech, Beijing, China). All constructs extracted from TOP10 E.coli cells were sequenced. 
Transfection was performed using LipoPlus ${ }^{\mathrm{TM}}$ Reagent (Sage creation science, Beijing, China) according to the manufacturer's instructions. Briefly, cells were seeded onto six-well plates one day before transfection and incubated in culture medium without antibiotics. When the confluence reached $₫ 50 \%$, cell transfection was performed. $2.5 \mu \mathrm{g} /$ well pcDNA3.1-vector or pcDNA3.1-AR recombinant plasmid and LipoPlus $^{\text {TM }}$ reagent were diluted with DMEM, respectively, and incubated at RT for $5 \mathrm{~min}$, then the diluted DNA were mixed with diluted LipoPlus ${ }^{\mathrm{TM}}$ reagent, and incubated for $30 \mathrm{~min}$ at RT, then the DNA-LipoPlus complex was added into cell medium. At $6 \mathrm{~h}$ after transfection finished, the cell culture medium was replaced with fresh medium containing FBS and antibiotics. The efficiency of transfection was determined by Western blot at $24 \mathrm{~h}$ after transfection finished.

\section{siRNA transfection}

Control and AR siRNA were purchased from Santa Cruz Biotechnology and transfected using Lipofectamine 2000 regent (Invitrogen, Carlsbad, CA, USA). C2C12 cells were seeded onto 6-well plates at

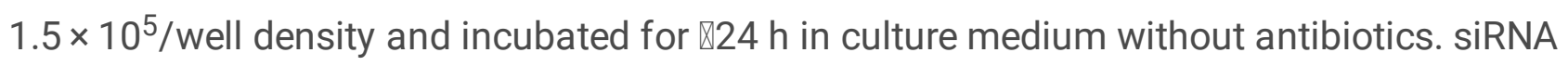
(100 pmol/well) and transfection regent $(10 \mu \mathrm{l} /$ well) were diluted with $250 \mu \mathrm{l} /$ well DMEM, respectively, then the diluted siRNA was added to transfection regent and mixed gently. And then the complex was added into cells containing $0.5 \mathrm{ml}$ medium without antibiotics following incubation for $20 \mathrm{~min}$ at RT. At $6 \mathrm{~h}$ after transfection, the medium was replaced with fresh medium containing FBS and antibiotics. Then at $36 \mathrm{~h}$ after transfection, cell proliferation and AR expression were detected by CCK8 and western blot, respectively.

\section{Cyclic mechanical stretches}

C2C12 and L6 myoblasts were stretched as described in our previous studies [17, 26]. Briefly, cells were plated onto flexible-bottomed 6-well plates pre-coated with type-I collagen (BioFlex, FlexCell International Corporation, USA) at a density of $1 \times 105 / \mathrm{ml}$ density and incubated for $24 \mathrm{~h}$ before exposing to mechanical strain. Cells were then subjected to cyclic mechanical stretch of $15 \%$ or $20 \%$ elongation at $0.5 \mathrm{~Hz}$ frequency for $6 \mathrm{~h}$ using a computer-controlled vacuum stretch apparatus (FX-5000T Tension System, FlexCell International Corporation). In parallel with identical experimental conditions, cells grown in flexible-bottomed 6-well plates but left un-stretched were considered as control.

\section{Cell proliferation assay}

Cell proliferation was measured by Cell Counting Kit-8 (CCK8) (Dojindo Laboratories, Kumamoto, Japan) following the manufacturer's protocols. At $24 \mathrm{~h}$ after mechanical stretches or transfection finished, culture medium was replaced with fresh cell culture medium, appropriate CCK8 was added into the medium in proportion, then the optical density (OD) values were detected at $450 \mathrm{~nm}$ after incubation for $2.5 \mathrm{~h}$ using a microplate reader (Biotek, Winooski, VT, USA).

\section{Determination of IGF-1 concentration}

Once stretch finished, culture medium was replaced by DMEM without FBS immediately and incubated for $24 \mathrm{~h}$, then cellular supernatant was collected and centrifuged at $12000 \mathrm{rpm}$ for $5 \mathrm{~min}$ at $4{ }^{\circ} \mathrm{C}$. IGF- 1 
concentration in cellular supernatant was determined by mouse/rat IGF-1 Quantikine ELISA Kit (R\&D Systems Inc, Minneapolis, MN, USA) according to manufacturer's instructions.

\section{Treatment with IGF-1 recombinant polypeptide}

To confirm the role of IGF-1 in the proliferation of stretched myoblasts, and its relationship with PI3K/Akt and MAPKs (p38 and ERK1/2), IGF-1 recombinant polypeptide with different concentrations $(200,500$, $1000 \mathrm{ng} / \mathrm{ml})[17,26]$ were added into culture medium before $15 \%$ stretch.

\section{Western blot}

Cells were harvested after culture and treatments, and total protein was extracted using RIPA lysis buffer (Beyotime Biotechnology, Shanghai, China) containing protease and phosphatase inhibitor cocktail (Beyotime Biotechnology, Shanghai, China). Protein concentration was determined by BCA protein assay kit (Beyotime Biotechnology, Shanghai, China). $30 \mu \mathrm{g}$ protein were separated on SDS-PAGE gel, and transferred to PVDF membranes (Millipore, Darmstadt, Germany). Membranes were blocked with $5 \%$ $(\mathrm{w} / \mathrm{v})$ fat-free milk in TBS/0.1\% Tween-20 at RT for $2 \mathrm{~h}$, then the PVDF membranes were incubated with primary antibodies at $4{ }^{\circ} \mathrm{C}$ overnight: AR (sc-816, 1:500), IGF-1R (AF-305, 1:500), p-PI3K [p85 (Tyr 458)/p55 (Tyr 199), 4228S, 1:1000], PI3K (4257P, 1:1000), p-Akt (Ser 473, 4060S, 1:1000), Akt (4691P, 1:1000), p-p38 MAPK (Thr 180/Tyr 182, 4511S, 1:1000), p38 (8690P, 1:1000), p-p44/42 MAPK (Thr 202/Tyr 204, 4370P,1:1000), p44/42 MAPK (4695P, 1:1000). After washing three times with TBST, the PVDF membranes were incubated with secondary antibody at RT for $2 \mathrm{~h}$. After final washing with TBST, protein bands were visualized with ECL reagents (Merck Millipore, America).

\section{Statistical analysis}

All the experiments were repeated at least three times. Data were presented as mean \pm standard deviation (SD), and statistical analysis was performed by SPSS 21.0. Statistical differences among experimental groups were determined by two-way ANOVA, and differences between two groups were analyzed by using Student's $t$ test. $p<0.05$ was consider as statistically significant.

\section{Results}

\section{Under un-stretched state, AR deficiency slows down the proliferation rate of myoblasts}

We first confirmed that AR expressed in C2C12 myoblasts whereas no detectable AR was examined in L6 myoblasts (Fig. 1A), consistent with previous studies. Then the proliferation of $\mathrm{C} 2 \mathrm{C} 12$ and L6 cells under un-stretched state were compared, and observed that the proliferation rate of L6 cells was significantly lower than that in $\mathrm{C} 2 \mathrm{C} 12$ cells, as evidenced by the number of L6 myoblasts were about $80.6 \%$ and $72.5 \%$ of $\mathrm{C} 2 \mathrm{C} 12$ myoblasts at $24 \mathrm{~h}$ and $48 \mathrm{~h}$ after seeding, respectively. To further clarify AR's roles in myoblasts proliferation, we explored the impacts of exogenous transfection AR into L6 myoblasts and AR knockdown in $\mathrm{C} 2 \mathrm{C} 12$ myoblasts on their proliferation, and found that the proliferation was promoted in L6 myoblasts by transfection with AR overexpression plasmid (Fig. 1B) while inhibited in C2C12 
myoblasts by AR knockdown utilizing siRNA AR (Fig. 1C). These results demonstrated that AR played an important role in myoblasts proliferation under un-stretched state.

\section{The degrees of $15 \%$ stretch-induced pro-proliferation and $20 \%$ stretch-induced anti-proliferation in L6 myoblasts are different from that in $\mathrm{C} 2 \mathrm{C} 12$ myoblasts}

Our previous work has reported that $15 \%$ and $20 \%$ stretches promoted and inhibited the proliferation of C2C12 myoblasts (with AR expression), respectively [17]. In the current study, the proliferation of L6 myoblasts (without AR expression) undertaken $15 \%$ or $20 \%$ stretch was detected, and we were surprised to found that $15 \%$ and $20 \%$ stretches promoted and inhibited (rather than no influence) the proliferation of L6 myoblasts, respectively; but compared to $\mathrm{C} 2 \mathrm{C} 12$ myoblasts, $15 \%$ stretch-induced pro-proliferative effect on L6 myoblasts was much lower (less than half of C2C12 cells), while $20 \%$ stretch-induced antiproliferation on L6 myoblasts was obvious higher (above 2-fold of $\mathrm{C} 2 \mathrm{C} 12$ cells) (Fig. 2), which indicated an important role of AR in stretch-modulated proliferation of myoblasts.

\section{AR overexpression promotes $15 \%$ stretch-induced pro-proliferation, and reverses $20 \%$ stretch-induced anti- proliferation in L6 myoblasts}

AR protein could be obviously detected in L6 myoblasts after transfection with AR overexpression plasmid (Fig. 3). AR overexpression further enhanced the proliferation of 15\% stretched L6 myoblasts by approximately $50 \%$ (Fig. 3A), reaching similar pro-proliferation degree of $15 \%$ stretched $\mathrm{C} 2 \mathrm{C} 12$ myoblasts (Fig. 3B), and reversed the anti-proliferation of $20 \%$ stretch on L6 myoblasts (Fig. 4).

\section{AR's role in 15\% stretch-induced pro-proliferation is fulfilled via activating p38 and ERK1/2 rather than PI3K/Akt}

To clarify relevant signal pathways involved in AR's roles in $15 \%$ stretch-induced pro-proliferation, the increased degrees of activities of PI3K/Akt, ERK1/2 and p38 were compared between C2C12 and L6 myoblasts subjected to $15 \%$ stretch, and we found that there was no difference in PI3K activity between the two cells but the increment of ERK1/2 activity in L6 myoblasts was lower (almost half) than that in C2C12 myoblasts, and what's more interesting was that p38 activity had no change in 15\% stretched L6 cells but about 2 folds increase in $15 \%$ stretched $\mathrm{C} 2 \mathrm{C} 12$ myoblasts (Fig. $5 \mathrm{~A}$ ). These results indicated that activated ERK1/2 and p38 (especially p38) but not PI3K were associated with AR's pro-proliferative effect on $15 \%$ stretched myoblasts.

Furthermore, the activations of those above molecules in L6 cells were detected after AR overexpression plasmid transfection, and we found that accompanied with proliferation increase of L6 cells (Fig. 3), the activities of p38 and ERK1/2, especially p38 activity were remarkable increased (Fig. 5C), demonstrating AR's role in promoting the proliferation of $15 \%$ stretched myoblasts was via activating p38 and ERK1/2. In addition, although there was no difference in 15\% stretch-induced increase in PI3K/Akt activations between $\mathrm{C} 2 \mathrm{C} 12$ and $\mathrm{L} 6$ myoblasts, exogenous AR could further increase the activities of PI3K/Akt in 15\% stretched L6 myoblasts (Fig. 5B). 
Effect of decreased AR on $20 \%$ stretch-induced anti-proliferation is mediated by inhibiting p38 instead of ERK1/2 and PI3K/Akt

To identify relevant signal molecules involved in decreased AR's roles in $20 \%$ stretch-induced antiproliferation on myoblasts, we compared the discrepancy between $\mathrm{C} 2 \mathrm{C} 12$ and L6 myoblasts subjected to $20 \%$ stretch in the activities of PI3K, p38 and ERK1/2, and found that the attenuated degree of p38 activity by $20 \%$ stretch was higher in L6 myoblasts than that in C2C12 myoblasts (approximately 5.7 folds), while the decreases of PI3K and ERK's activities resulted from $20 \%$ stretch were similar to that in C2C12 cells (Fig. 6A), which indicated that the activation of p38 but not PI3K and ERK was related to decreased AR's anti-proliferation on $20 \%$ stretched myoblasts.

Furthermore, transfection with AR overexpression plasmid into $20 \%$ stretched L6 myoblasts led to an enormous enhancement in p38 activity while mild increases in the activations of PI3K, Akt and ERK1/2 (Fig. 6B and 6C), demonstrated that the anti-proliferative effect of decreased AR on $20 \%$ stretched myoblasts was via inhibiting $\mathrm{p} 38$ activation (instead of ERK1/2 and PI3K's activations).

\section{AR overexpression up-regulates IGF-1R levels but not IGF-1 secretion of L6 myoblasts subjected to $15 \%$ or $20 \%$ stretch}

IGF-1 secretion from L6 myoblasts undertaken $15 \%$ or $20 \%$ stretch were determined after transfection with AR overexpression plasmid, and still no detectable IGF-1 was secreted. For IGF-1R, significant increase and decrease of IGF-1R protein levels were observed in L6 myoblasts subjected to 15\% (Fig. 7A) and $20 \%$ (Fig. 7B) stretches, respectively. AR overexpression enhanced the IGF-1R levels in both $15 \%$ and $20 \%$ stretched L6 myoblasts (Fig. 7).

Exogenous IGF-1 recombinant polypeptide further increases IGF-1R protein level and the activities of PI3K/Akt and MAPKs (p38 and ERK1/2) in 15\% stretched L6 myoblasts, accompanied with the enhanced proliferation.

Exogenous IGF- 1 recombinant polypeptide with various concentrations $(200,500$, and $1000 \mathrm{ng} / \mathrm{ml})$ were incubated with cells to verify the regulation of IGF-1 on the proliferation as well as PI3K/Akt, p38 and ERK1/2 signals in 15\% stretch myoblasts. As shown in Fig.8, IGF-1 recombinant polypeptide further promoted the proliferation of $15 \%$ stretched $\mathrm{L} 6$ myoblasts in a dose-dependent manner (Fig. 8A), accompanied with dose-dependent increases in protein level of IGF-1R (Fig. 8B) and in activities of PI3K, Akt, p38 and ERK1/2 (increased phosphorylated protein levels of PI3K, Akt, p38 and ERK1/2) (Fig. 8C and 8D).

\section{Discussion}

\section{AR's roles in the proliferation of myoblasts by appropriate stretch and over-stretch}

Satellite cells or myoblasts exert crucial roles in muscle hypertrophy, and impairments in the proliferation and differentiation of these cells cause muscle atrophy. Exercise-induced muscle hypertrophy is also 
associated with the increased proliferation of satellite cells [27], furthermore, satellite cell depletion blockades exercise-induced muscle hypertrophy $[28,29]$. In vitro, exposing satellite cells or myoblasts to mechanical stretch is usually used to mimic the stimulation of exercise on muscle, and multiple lines of evidences in vitro including our previous work have demonstrated that appropriate mechanical stretch with several deformations $(10 \%, 15 \%$ or $17 \%)$, frequencies $(0.25 \mathrm{~Hz}$ or $0.5 \mathrm{~Hz})$ and durations $(1 \mathrm{~h}$ or $2 \mathrm{~h})$ promotes the proliferation of primary satellite cells or mouse $\mathrm{C} 2 \mathrm{C} 12$ myoblasts $[17,30]$, while excessive mechanical stretch inhibits the proliferation of the above cells when deformation increased up to $20 \%$ [17], even lead to cell apoptosis [31]. So $15 \%$ and $20 \%$ stretches are chosen in our experiments to mimic appropriate exercise and overtraining respectively.

As mentioned in the Introduction, our previous work revealed that in $\mathrm{C} 2 \mathrm{C} 12$ myoblasts (expressed AR), $15 \%$ stretch-induced pro-proliferation was likely to be mediated by up-regulation of AR because AR specific antagonist flutamide attenuated the pro-proliferation of $15 \%$ stretch on $\mathrm{C} 2 \mathrm{C} 12$ myoblasts in a dose-dependent manner. Meanwhile, $20 \%$ stretch-induced anti-proliferation was accompanied with the down-regulation of AR [17]. What's interesting is that another commonly used L6 myoblasts, which has no detectable AR, reported to promoted and inhibited the proliferation after $15 \%$ and $20 \%$ stretches respectively [26], showed different proliferative characteristics-lower pro-proliferation by $15 \%$ stretch and higher anti-proliferation by $20 \%$ stretch compared with C2C12 myoblasts, which has AR expression. Furthermore, transfection with AR overexpression plasmid significantly enhanced the pro-proliferation of $15 \%$ stretch on L6 cells (closing to the identical level of 15\% stretched C2C12 cells), and totally reversed the anti-proliferation of $20 \%$ stretch on L6 cells. These results demonstrated key and indispensable effects of elevated AR in 15\% stretch-induced pro-proliferation of myoblasts and of reduced AR in $20 \%$ stretch-induced anti-proliferation of myoblasts.

In addition, under un-stretched condition, the proliferation rate of $L 6$ myoblasts was lower than that of C2C12 myoblasts (about $80.6 \%$ and $72.5 \%$ of $\mathrm{C} 2 \mathrm{C} 12$ myoblasts at $24 \mathrm{~h}$ and $48 \mathrm{~h}$ after seeding). And AR knockdown by siRNA inhibited the proliferation of $\mathrm{C} 2 \mathrm{C} 12$ myoblasts, while transfection with $\mathrm{AR}$ overexpression plasmid increased the proliferation of L6 myoblasts, implied the important role of AR in proliferation of un-stretched myoblasts.

\section{The mechanisms of AR's effects on stretches-regulated proliferation of myoblasts}

It is well known that AR affects muscle mass through genomic and non-genomic mechanisms. Recently, non-genomic mechanism of AR has been proven to be crucial in promoting myoblasts proliferation and increasing muscle mass through interactions with other signaling molecules such as IGF-1 and its downstream molecules [32]. PI3K/Akt and MAPKs (p38 and ERK1/2) are common downstream molecules of IGF-1, and IGF-1 promotes the proliferation of primary satellite cell or myoblast via activating PI3K/Akt and MAPKs (p38 and ERK1/2), specific inhibitors of PI3K (LY294002), p38 (SB203580) and ERK1/2 (U0126) blocked the pro-proliferative effect of IGF-1 [17, 19, 21]. In addition, several microRNA-induced myotubes atrophy and proliferation inhibition of bovine myoblasts were related to down-regulated IGF-1, thus suppressing PI3K/Akt signal pathway [33, 34]. 
Not only that, recent studies showed the importance of PI3K/Akt, p38 and ERK1/2 MAPKs in the anabolic action of AR, which was partly fulfilled through the crosstalk with AR [35-37]. Testosterone promotes muscle hypertrophy via activating PI3K/Akt [35], ERK1/2 [38] and p38 MAPK [39], and administration of specific inhibitors of PI3K (LY294002) and p38 (SB203580) blocked the testosterone's effects. In fact, in addition to AR-induced myotube hypertrophy, testosterone-induced differentiation (increases of myotube number and diameter) of fusion impaired $\mathrm{C} 2 \mathrm{C} 12$ myoblasts is also associated with the activation of $\mathrm{PI3K} / \mathrm{Akt}$ [37] and androgen/AR-participated skeletal muscle glucose metabolism is related to the activations of Akt and ERK1/2 signal pathways [36].

The above situations are involved in non-exercise conditions or un-stretched myoblasts, what about the mechanisms of AR in appropriate stretch and overstretch condition? Whether IGF-1- mediated PI3K/Akt and MAPKs (p38 and ERK1/2) pathways still play key roles in the effects of AR on the two stretchesmodulated proliferation of myoblasts and does there exist difference with regard to signal pathways involved in $15 \%$ and $20 \%$ stretches-regulated proliferation of myoblasts? Our previous work in $15 \%$ stretched $\mathrm{C} 2 \mathrm{C} 12$ myoblasts indicated that the effect of increased AR on pro-proliferation was fulfilled by IGF-1 mediated activations of PI3K/Akt, p38 and ERK1/2 using IGF-1 neutralized antibody and specific inhibitors of PI3K/Akt, p38 and ERK1/2 [17]; for 20\% stretch-induced anti-proliferation of C2C12 myoblasts, the decrease of AR might exert its role through inhibiting IGF-1 secretion using IGF-1 recombinant polypeptide [17]. However, the AR's effects on $15 \%$ and $20 \%$ stretches-modulated proliferation of myoblasts and the mechanisms require further confirmation.

So in this paper the discrepancies between myoblasts $\mathrm{L} 6$ (without AR) and $\mathrm{C} 2 \mathrm{C} 12$ (with AR) were compared in the proliferation, the levels of IGF-1/IGF-1R, and the levels and activations of PI3K/Akt, p38 and ERK $1 / 2$ after $15 \%$ or $20 \%$ stretch, then the above indicators in L6 myoblasts were detected again after transfection with AR overexpression plasmid or treatment with IGF-1 recombinant polypeptide. Except for similar elevated degree of PI3K activity induced by $15 \%$ stretch between L6 and C2C12 myoblasts, obvious differences were found between the two myoblasts after $15 \%$ stretch, including: (1) IGF-1: increased secretion in C2C12 myoblasts while no secretion in L6 myoblasts; (2) ERK1/2 activity: increased degree in L6 myoblasts was half of that in C2C12 myoblasts; (3) p38 activity: no change in L6 myoblasts but beyond 3-fold elevation in $\mathrm{C} 2 \mathrm{C} 12$ myoblasts. Furthermore, transfection L6 myoblasts with AR overexpression plasmid and treatment with IGF-1 recombinant polypeptide both enhanced the level of IGF-1R (although still no IGF-1 secretion), and the activations of p38 and ERK1/2 in 15\% stretched L6 myoblasts, accompanied with the further promotion of $L 6$ proliferation. These results indicated that the pro-proliferative effect of AR on $15 \%$ stretched myoblasts was mediated through increasing IGF-1R, thus activating the activities of $\mathrm{p} 38$ and ERK1/2, especially $\mathrm{p} 38$, rather than PI3K/Akt pathway.

For $20 \%$ stretch, our previous studies revealed significant decreases including the secretion of IGF-1 and the activations of PI3K/Akt, p38 and ERK1/2 in 20\% stretched C2C12 myoblasts [17]. In the present study, there was no difference in the inhibition degree of PI3K/Akt and ERK1/2's activations between $20 \%$ stretched L6 and C2C12 myoblasts, but remarkable discrepancies were found after $20 \%$ stretch between the two myoblasts, including: (1) IGF-1: decreased secretion in C2C12 myoblasts while still no secretion in 
L6 myoblasts; (2) p38 activity: about 6.7-fold decrease in L6 myoblasts than C2C12 myoblasts. Furthermore, transfection with AR overexpression plasmid and IGF-1 recombinant polypeptide both increased the level of IGF-1R and the activities of p38, accompanied with the reverse of $20 \%$ stretchinduced anti-proliferation of L6 myoblasts. The above results indicated that declined AR mediated the proliferation inhibition of $20 \%$ stretch on myoblasts, which was achieved via suppressing IGF-1R, thus inhibiting p38 activation. It is interesting to find a discrepancy in signal pathways fulfilling AR's role in $20 \%$ and $15 \%$ stretches modulated myoblasts proliferation (inhibiting AR- IGF-1R-p38 pathway vs activating AR- IGF-1R- p38 and ERK1/2 pathway).

\section{Conclusions}

The present study demonstrated AR's crucial roles in $15 \%$ and $20 \%$ stretches induced pro-proliferation and anti-proliferation of myoblasts, via activating AR- IGF-1R- p38 and ERK1/2 pathways and inhibiting AR- IGF-1R- p38 pathway respectively. This study is beneficial to understand in depth the role and mechanisms of AR on appropriate exercise increases while excessive exercise decreases muscle mass.

\section{Abbreviations}

Akt: protein kinase B; AR: androgen receptor; AREs: androgen response elements; CCK8: Cell Counting Kit8; ERK1/2: extracellular signal-regulated kinases 1 and 2; IGF-1: insulin-like growth factor; IGF-1R: insulinlike growth factor receptor; MAPK: mitogen-activated protein kinase; PI3K: phosphoinositide 3-kinases; SARMs: selective androgen receptor modulators.

\section{Declarations}

\section{Ethics approval and consent to participate}

Not applicable.

\section{Consent for publication}

Not applicable.

\section{Availability of data and materials}

All data generated or analyzed during this study are available from the corresponding author on reasonable request.

\section{Competing interests}

The authors declare that they have no competing interests.

\section{Funding}


This work was supported by grants from the National Natural Science Foundation of China (No. 31872801) and by Shanghai Key Lab of Human Performance (Shanghai University of sport) (NO.11DZ2261100).

\section{Authors' contributions}

Xiaohui Wang conception and design of research; Shaoting Fu, Xiaojing Lin and Lijun Yin performed experiments, analyzed data and interpreted results of experiments; Shaoting Fu drafted manuscript, and Xiaohui Wang edited and revised manuscript. All authors approved the final version of the paper.

\section{Acknowledgements}

Not applicable.

\section{Authors' details}

${ }^{1}$ Department of Exercise Physiology, School of Kinesiology, Shanghai University of Sport, Shanghai, China. ${ }^{2}$ Department of Kinesiology, College of Physical Education, Shanghai Normal University, Shanghai, China.

\section{References}

1. Storer TW, Basaria S, Traustadottir T, Harman SM, Pencina K, Li Z, et al. Effects of Testosterone Supplementation for 3 Years on Muscle Performance and Physical Function in Older Men. The Journal of clinical endocrinology and metabolism. 2017;102(2):583-

93.https://academic.oup.com/jcem/article/102/2/583/2972073

2. Sinclair M, Grossmann M, Hoermann R, Angus PW, Gow PJ. Testosterone therapy increases muscle mass in men with cirrhosis and low testosterone: A randomised controlled trial. Journal of hepatology. 2016;65(5):906-13.

https://www.sciencedirect.com/science/article/pii/S0168827816302690?via\%3Dihub

3. Mumford PW RM, Mao X, Mobley CB, Kephart WC, Haun CT, Roberson PA, Young KC1, Martin JS1, Yarrow JF, Beck DT, Roberts MD. Cross talk between androgen and Wnt signaling potentially contributes to age-related skeletal muscle atrophy in rats. J Appl Physiol (1985). 2018;125(2):48694.https://journals.physiology.org/doi/full/10.1152/japplphysiol.00768.2017

4. Rana K, Davey RA, Zajac JD. Human androgen deficiency: insights gained from androgen receptor knockout mouse models. Asian J Androl. 2014;16(2):169-

77.https://www.ajandrology.com/article.asp?issn=1008-

682X;year=2014; volume=16;issue=2; spage=169; ;page=177; aulast=Rana

5. MacLean HE, Chiu WS, Notini AJ, Axell AM, Davey RA, McManus JF, et al. Impaired skeletal muscle development and function in male, but not female, genomic androgen receptor knockout mice.

FASEB J. 2008;22(8):2676-89. https://faseb.onlinelibrary.wiley.com/doi/full/10.1096/fj.08-105726 
6. Dubois V, Laurent MR, Sinnesael M, Cielen N, Helsen C, Clinckemalie L, et al. A satellite cell-specific knockout of the androgen receptor reveals myostatin as a direct androgen target in skeletal muscle. FASEB J. 2014;28(7):2979-94. https://faseb.onlinelibrary.wiley.com/doi/full/10.1096/fj.14-249748

7. Ponnusamy S, Sullivan RD, You D, Zafar N, He Yang C, Thiyagarajan T, et al. Androgen receptor agonists increase lean mass, improve cardiopulmonary functions and extend survival in preclinical models of Duchenne muscular dystrophy. Human molecular genetics. 2017;26(13):2526-40. https://academic.oup.com/hmg/article/26/13/2526/3770516

8. Neil D, Clark RV, Magee M, Billiard J, Chan A, Xue Z, et al. GSK2881078, a SARM, Produces DoseDependent Increases in Lean Mass in Healthy Older Men and Women. The Journal of clinical endocrinology and metabolism. 2018;103(9):3215-24. https://academic.oup.com/jcem/article/103/9/3215/5047294

9. Gagliano-Juca T, Basaria S. Testosterone replacement therapy and cardiovascular risk. Nature reviews Cardiology. 2019. https://www.nature.com/articles/s41569-019-0211-4

10. Son BK, Eto M, Oura M, Ishida Y, Taniguchi S, Ito K, et al. Low-Intensity Exercise Suppresses CCAAT/Enhancer-Binding Protein $\delta /$ Myostatin Pathway Through Androgen Receptor in Muscle Cells. Gerontology. 2019:1-10. https://www.karger.com/Article/Abstract/499826

11. Morton RW, Sato K, Gallaugher MPB, Oikawa SY, McNicholas PD, Fujita S, et al. Muscle Androgen Receptor Content but Not Systemic Hormones Is Associated With Resistance Training-Induced Skeletal Muscle Hypertrophy in Healthy, Young Men. Front Physiol. 2018;9:1373. https://www.frontiersin.org/articles/10.3389/fphys.2018.01373/full

12. Ferry A, Schuh M, Parlakian A, Mgrditchian T, Valnaud N, Joanne P, et al. Myofiber androgen receptor promotes maximal mechanical overload-induced muscle hypertrophy and fiber type transition in male mice. Endocrinology. 2014;155(12):4739-48.

https://academic.oup.com/endo/article/155/12/4739/2423067

13. Yin L, Lu L, Lin $X$, Wang $X$. Crucial role of androgen receptor in resistance and endurance trainingsinduced muscle hypertrophy through IGF-1/IGF-1R-PI3K/Akt- mTOR pathway. Nutr Metab (Lond). 2020;17:26. https://nutritionandmetabolism.biomedcentral.com/articles/10.1186/s12986-02000446-y

14. da Rocha AL, Pereira BC, Teixeira GR, Pinto AP, Frantz FG, Elias LLK, et al. Treadmill Slope Modulates Inflammation, Fiber Type Composition, Androgen, and Glucocorticoid Receptors in the Skeletal Muscle of Overtrained Mice. Frontiers in immunology. 2017;8:1378. https://www.frontiersin.org/articles/10.3389/fimmu.2017.01378/full

15. Rana K, Lee NK, Zajac JD, MacLean HE. Expression of androgen receptor target genes in skeletal muscle. Asian journal of andrology. 2014;16(5):675-83. https://www.ajandrology.com/article.asp? issn $=1008-682 X$; year $=2014$; volume $=16$; issue $=5$; ppage $=675$;epage $=683$; aulast $=$ Rana

16. Lee NK SJ, Zajac JD, MacLean HE. Ornithine decarboxylase is upregulated by the androgen receptor in skeletal muscle and regulates myoblast proliferation. Am J Physiol Endocrinol Metab. 2011;301(1):E172-9. https://journals.physiology.org/doi/full/10.1152/ajpendo.00094.2011 
17. Ma Y, Fu S, Lu L, Wang X. Role of androgen receptor on cyclic mechanical stretch-regulated proliferation of $\mathrm{C} 2 \mathrm{C} 12$ myoblasts and its upstream signals: IGF-1-mediated PI3K/Akt and MAPKs pathways. Mol Cell Endocrinol. 2017;450:83-

93.https://www.sciencedirect.com/science/article/pii/S0303720717302447?via\%3Dihub

18. Fu R, Liu J, Fan J, Li R, Li D, Yin J, et al. Novel evidence that testosterone promotes cell proliferation and differentiation via $\mathrm{G}$ protein-coupled receptors in the rat $\mathrm{L} 6$ skeletal muscle myoblast cell line. Journal of cellular physiology. 2012;227(1):98-107.

19. Yu M, Wang H, Xu Y, Yu D, Li D, Liu X, et al. Insulin-like growth factor-1 (IGF-1) promotes myoblast proliferation and skeletal muscle growth of embryonic chickens via the PI3K/Akt signalling pathway. Cell biology international. 2015;39(8):910-22.

20. Heron-Milhavet L, Mamaeva D, LeRoith D, Lamb NJ, Fernandez A. Impaired muscle regeneration and myoblast differentiation in mice with a muscle-specific KO of IGF-IR. Journal of cellular physiology. 2010;225(1):1-6.

21. Ge X, Zhang Y, Jiang H. Signaling pathways mediating the effects of insulin-like growth factor-I in bovine muscle satellite cells. Mol Cell Endocrinol. 2013;372(1-2):23-9. https://www.sciencedirect.com/science/article/pii/S0303720713001135?via\%3Dihub

22. Mackrell JG, Yaden BC, Bullock H, Chen $\mathrm{K}$, Shetler $\mathrm{P}$, Bryant $\mathrm{HU}$, et al. Molecular targets of androgen signaling that characterize skeletal muscle recovery and regeneration. Nuclear receptor signaling. 2015;13:e005. https://journals.sagepub.com/doi/10.1621/nrs.13005

23. Serra C, Bhasin S, Tangherlini F, Barton ER, Ganno M, Zhang A, et al. The role of GH and IGF-I in mediating anabolic effects of testosterone on androgen-responsive muscle. Endocrinology. 2011;152(1):193-206. https://academic.oup.com/endo/article/152/1/193/2456621

24. Lee WJ. Insulin-like growth factor-l-induced androgen receptor activation is mediated by the PI3K/Akt pathway in C2C12 skeletal muscle cells. Mol Cells. 2009;28(5):495-9.

25. Kim HJ, Lee WJ. Ligand-independent activation of the androgen receptor by insulin-like growth factor-I and the role of the MAPK pathway in skeletal muscle cells. Mol Cells. 2009;28(6):589-93.

26. Fu S, Yin L, Lin X, Lu J, Wang X. Effects of Cyclic Mechanical Stretch on the Proliferation of L6 Myoblasts and Its Mechanisms: PI3K/Akt and MAPK Signal Pathways Regulated by IGF-1 Receptor. Int J Mol Sci. 2018;19(6).

27. Fujimaki S, Machida M, Wakabayashi T, Asashima M, Takemasa T, Kuwabara T. Functional Overload Enhances Satellite Cell Properties in Skeletal Muscle. Stem cells international. 2016;2016:7619418. https://www.hindawi.com/journals/sci/2016/7619418/

28. Egner IM, Bruusgaard JC, Gundersen K. Satellite cell depletion prevents fiber hypertrophy in skeletal muscle. Development. 2016;143(16):2898-906.

29. Goh Q, Song T, Petrany MJ, Cramer AA, Sun C, Sadayappan S, et al. Myonuclear accretion is a determinant of exercise-induced remodeling in skeletal muscle. eLife. 2019;8.

30. Kook SH SY, Choi KC, Lee HJ, Chung WT, Hwang IH, Lee JC. Cyclic mechanical stress suppresses myogenic differentiation of adult bovine satellite cells through activation of extracellular signal- 
regulated kinase. Mol Cell Biochem. 2008;309(1-2):133-41.

31. Song J, Zhang Q, Wang S, Yang F, Chen Z, Dong Q, et al. Cleavage of caspase-12 at Asp94, mediated by endoplasmic reticulum stress (ERS), contributes to stretch-induced apoptosis of myoblasts. Journal of cellular physiology. 2018;233(12):9473-87.

32. Moriwaki K, Matsumoto H, Tanishima S, Tanimura C, Osaki M, Nagashima H, et al. Association of serum bone- and muscle-derived factors with age, sex, body composition, and physical function in community-dwelling middle-aged and elderly adults: a cross-sectional study. BMC Musculoskeletal Disorders. 2019;20(1).

33. Song C, Yang Z, Dong D, Xu J, Wang J, Li H, et al. miR-483 inhibits bovine myoblast cell proliferation and differentiation via IGF1/PI3K/AKT signal pathway. Journal of cellular physiology. 2019;234(6):9839-48.

34. Liu C, Wang M, Chen M, Zhang K, Gu L, Li Q, et al. miR-18a induces myotubes atrophy by downregulating Igfl. The international journal of biochemistry \& cell biology. 2017;90:145-54. https://www.sciencedirect.com/science/article/pii/S1357272517301838?via\%3Dihub

35. Deane CS, Hughes DC, Sculthorpe N, Lewis MP, Stewart CE, Sharples AP. Impaired hypertrophy in myoblasts is improved with testosterone administration. The Journal of steroid biochemistry and molecular biology. 2013;138:152-

61.https://www.sciencedirect.com/science/article/pii/S0960076013000769?via\%3Dihub

36. Antinozzi C, Marampon F, Corinaldesi C, Vicini E, Sgro P, Vannelli GB, et al. Testosterone insulin-like effects: an in vitro study on the short-term metabolic effects of testosterone in human skeletal muscle cells. Journal of endocrinological investigation. 2017;40(10):113343.https://link.springer.com/article/10.1007/s40618-017-0686-y

37. Hughes DC, Stewart CE, Sculthorpe N, Dugdale HF, Yousefian F, Lewis MP, et al. Testosterone enables growth and hypertrophy in fusion impaired myoblasts that display myotube atrophy: deciphering the role of androgen and IGF-I receptors. Biogerontology. 2016;17(3):619-39. https://link.springer.com/article/10.1007\%2Fs10522-015-9621-9

38. Wu Y, Bauman WA, Blitzer RD, Cardozo C. Testosterone-induced hypertrophy of L6 myoblasts is dependent upon Erk and mTOR. Biochem Biophys Res Commun. 2010;400(4):679-83. https://www.sciencedirect.com/science/article/pii/S0006291X10016487?via\%3Dihub

39. Brown D, Hikim AP, Kovacheva EL, Sinha-Hikim I. Mouse model of testosterone-induced muscle fiber hypertrophy: involvement of p38 mitogen-activated protein kinase-mediated Notch signaling. The Journal of endocrinology. 2009;201(1):129-

39.https://joe.bioscientifica.com/view/journals/joe/201/1/129.xml

\section{Figures}


A

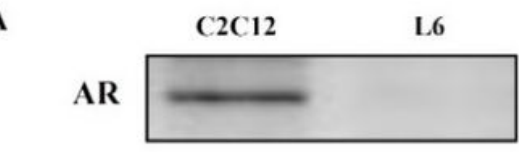

GAPDII
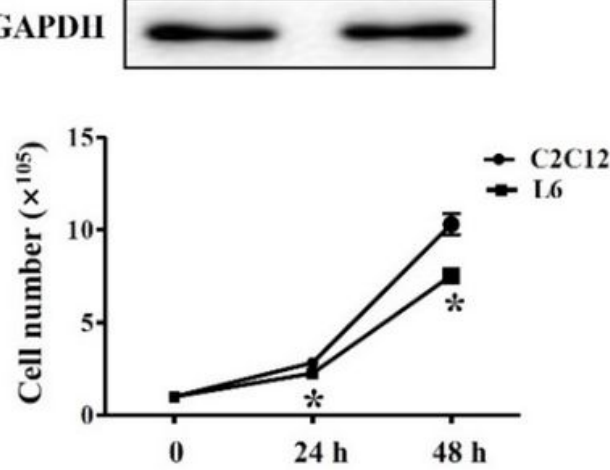

B
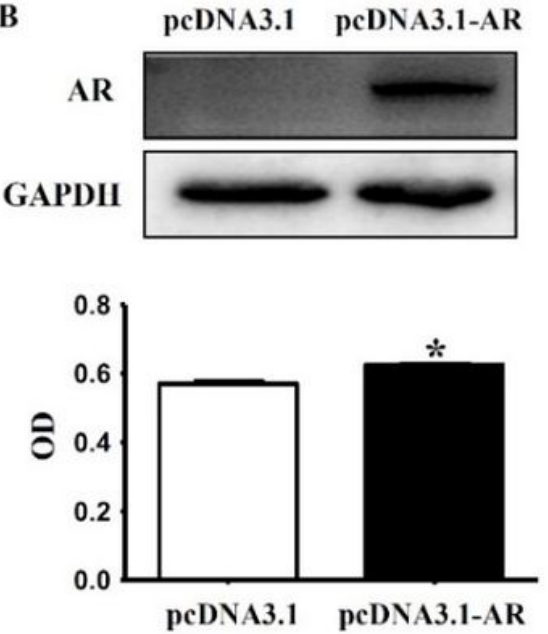

C
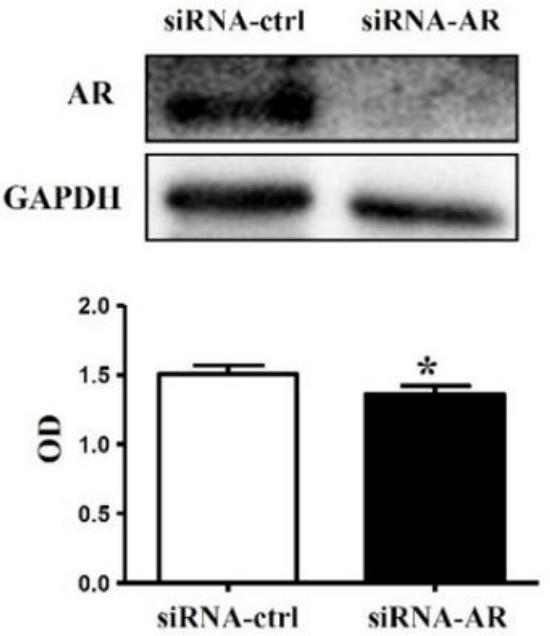

Figure 1

Under un-stretched state, AR deficiency slows down the proliferation rate of myoblasts. (A) The difference in AR level between C2C12 and L6 myoblasts was detected by Western blot (the upper) and the number of L6 and C2C12 myoblasts was determined by cell counting using hemocytometer (the lower), * $\mathrm{p}<0.05$ vs C2C12 myoblasts. (B) $2.5 \mathrm{ug} /$ well AR overexpression plasmid was transfected into L6 myoblasts using LipoPlusTM reagent, the level of AR protein (the upper) and the proliferation (the lower) of L6 myoblasts were determined at $24 \mathrm{~h}$ after transfection by Western blot and CCK8, respectively. ${ }^{*} \mathrm{p}<0.05$ vs L6 myoblasts transfection with pcDNA3.1 vector. (C) 100 pmol/well was transfected into C2C12 myoblasts using Lipofectamine 2000 regent, the level of AR protein (the upper) and the proliferation (the lower) of C2C12 myoblasts were detected at $36 \mathrm{~h}$ after transfection by Western blot and CCK8, * $\mathrm{p}<0.05 \mathrm{vs}$ C2C12 myoblasts transfection with control siRNA. The experiments were repeated at least three times, and the results were from three independent experiments and represented as mean $\pm S D$.

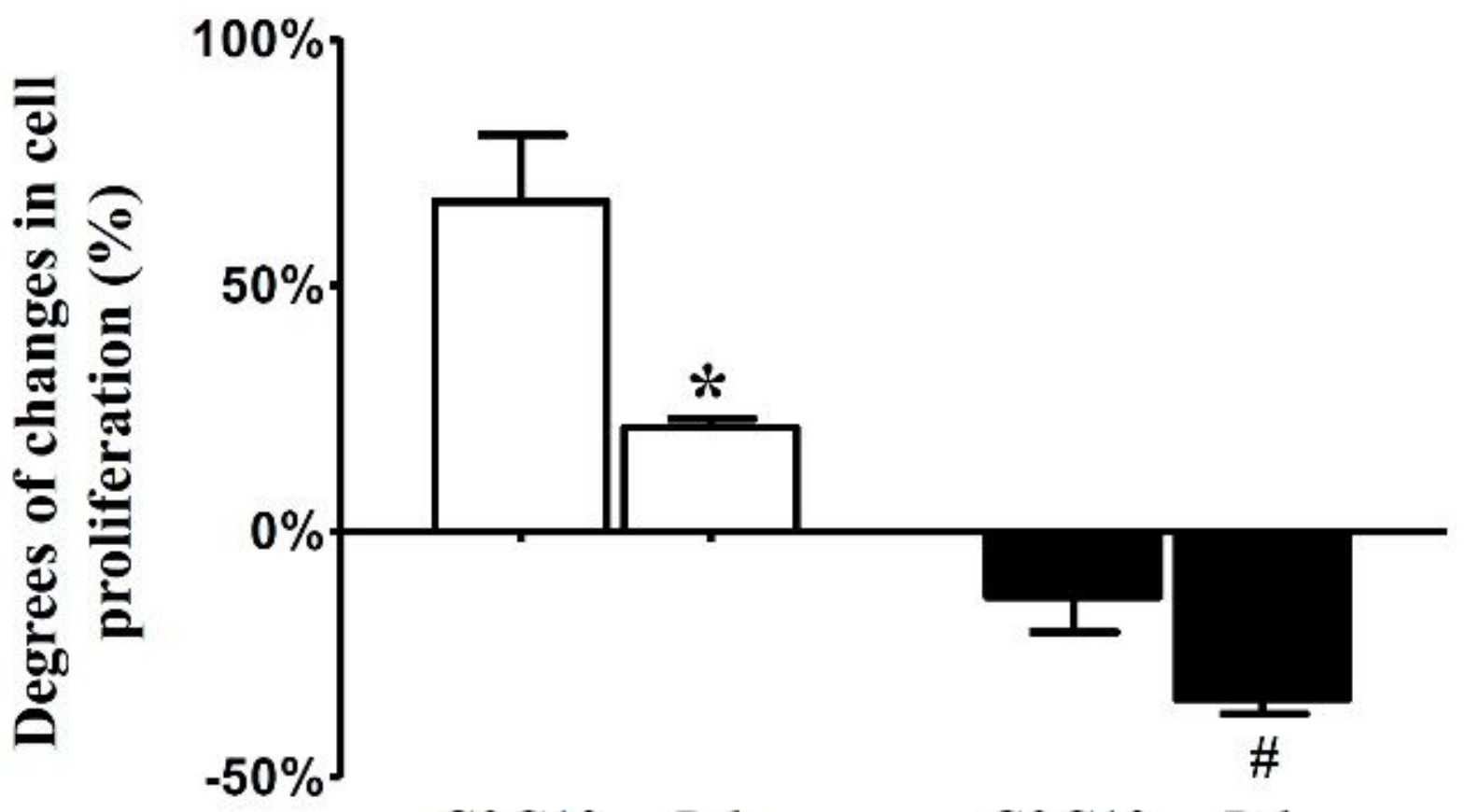
C2C12 L6
C2C12 L6 


\section{Figure 2}

Different pro- and anti-proliferation degrees between L6 and C2C12 myoblasts undertaken 15\% and 20\% stretches. L6 or $\mathrm{C} 2 \mathrm{C} 12$ myoblasts were seeded onto a flexible-bottomed 6-well plate and subjected to $15 \%$ or $20 \%$ stretch, then the proliferation of L6 and C2C12 cells were detected by CCK 8 at $24 \mathrm{~h}$ after stretch finished. The alteration degrees of $15 \%$ stretch-induced pro-proliferation and $20 \%$ stretch-induced antiproliferation were compared between $\mathrm{C} 2 \mathrm{C} 12$ and L6 myoblasts using the following formula: $=(\mathrm{OD} 15 \%$ or $20 \%$ stretch - ODCON)/ODCON. The experiments were repeated at least three times (mean $\pm S D, n=3$ ), * and \# indicated $\mathrm{p}<0.05$ vs corresponding $\mathrm{C} 2 \mathrm{C} 12$ cells. 
A
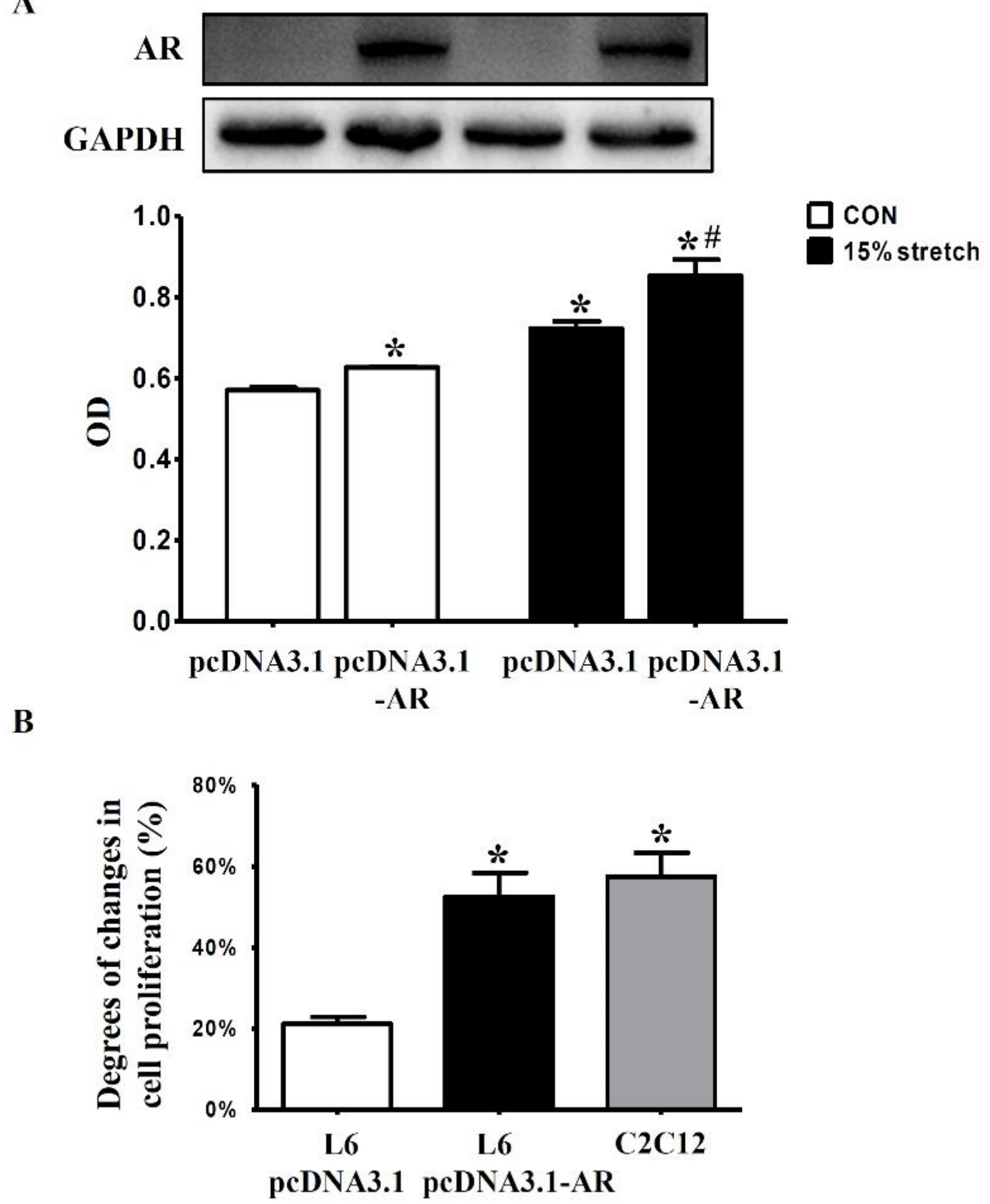

Figure 3

AR overexpression increases $15 \%$ stretch-induced pro-proliferation, reaching the pro-proliferation degree of 15\% stretched C2C12 myoblasts. (A) L6 myoblasts were seeded onto flexible-bottomed 6-well plates at $1 \times 105 / \mathrm{ml}$ density, when the confluence reached $₫ 50 \%, 2.5 \mu \mathrm{g}$ pcDNA3.1 vector or pcDNA3.1-AR recombinant plasmid was transfected into L6 myoblasts using LipoPlusTM reagent. At $24 \mathrm{~h}$ after transfection, L6 cells were subjected to 15\% stretch, the level of AR protein (the upper) and the 
proliferation (the lower) of L6 myoblasts were determined by Western Blot and CCK8 at $24 \mathrm{~h}$ after stretch finished, respectively. ${ }^{*}<<0.05$ vs CONpcDNA3.1; $\# p<0.05$ vs $15 \%$ stretchpcDNA3.1. (B) The proproliferation extents of $15 \%$ stretched $\mathrm{L} 6$ and $\mathrm{C} 2 \mathrm{C} 12$ cells were calculated using the formula:=(OD15\% stretch-ODCON)/ODCON; and for stretched L6 myoblasts transfection with pcDNA3.1-AR recombinant plasmid using the following formula:=(OD15\% stretch+pcDNA3.1-AR-

ODCON+pcDNA3.1)/ODCON+pcDNA3.1. ${ }^{*} p<0.05$ vs. L6 myoblasts transfected with pcDNA3.1 vector. The experiments were repeated at least three times, and the results were from three independent experiments and represented as mean \pm SD.

\section{AR}

\section{GAPDH}
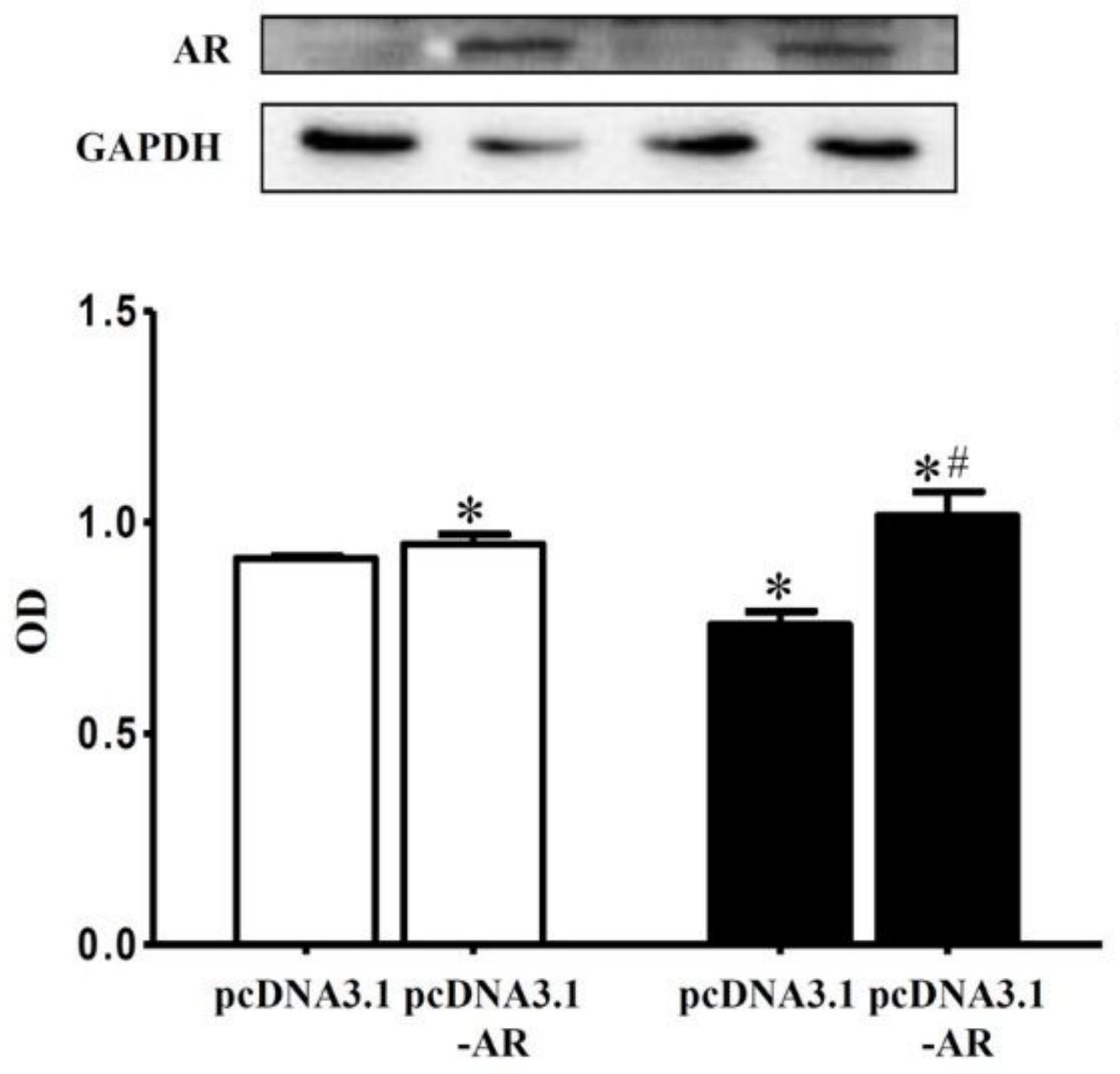

Figure 4

AR overexpression in L6 myoblasts reverses $20 \%$ stretch-induced anti-proliferation. L6 myoblasts were seeded onto flexible-bottomed 6 -well plates at $1 \times 105 / \mathrm{ml}$ density, when the confluence of cells reached $\nabla$ $50 \%$, pcDNA3. 1 vector or pcDNA3.1-AR recombinant plasmid was transfected into L6 cells, then L6 cells were subjected to $20 \%$ stretch at $24 \mathrm{~h}$ after transfection, and the level of AR protein and cell proliferation were detected at $24 \mathrm{~h}$ after stretch finished by Western blot and CCK8, respectively. The results were from 
three independent experiments and represented as mean $\pm S D$, ${ }^{\star} p<0.05$ vs CONpcDNA3.1; $\# p<0.05$ vs $20 \%$ stretch pcDNA3.1.

A

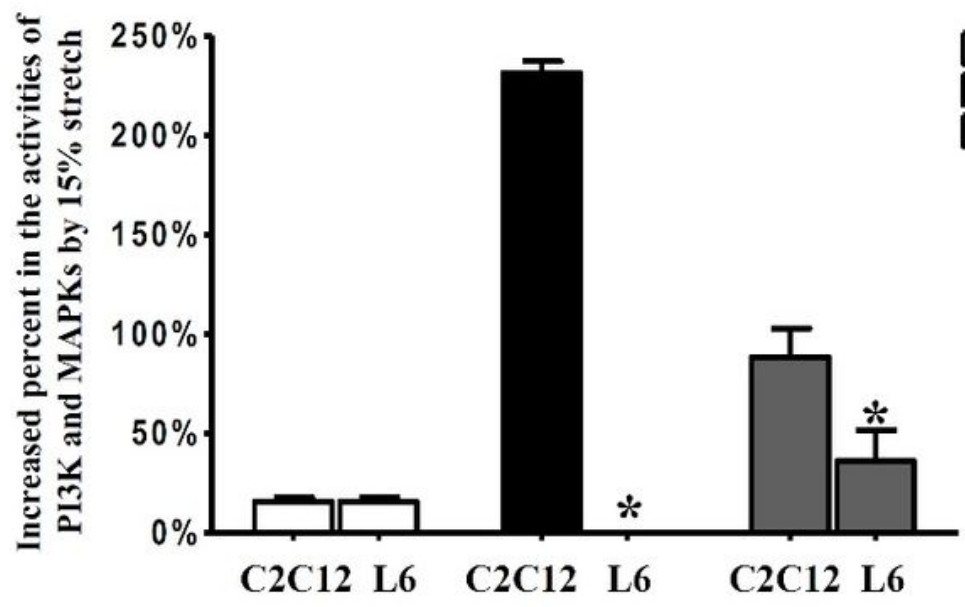

B
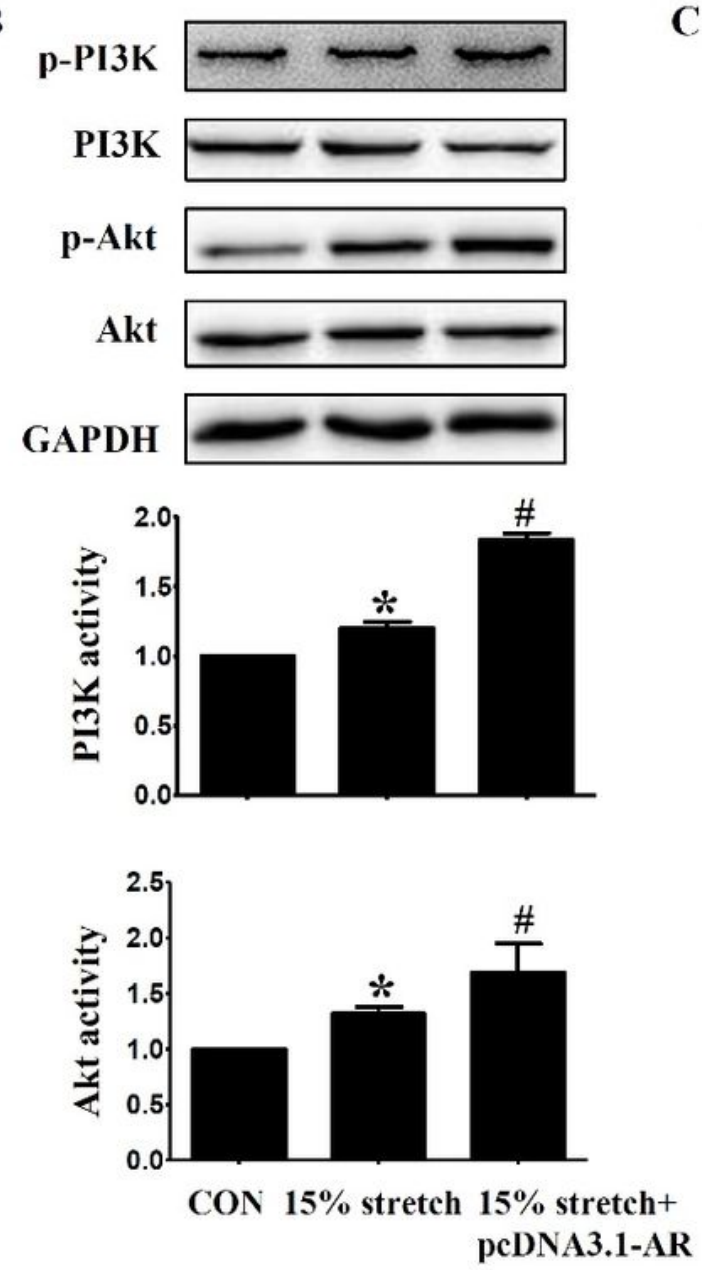

C
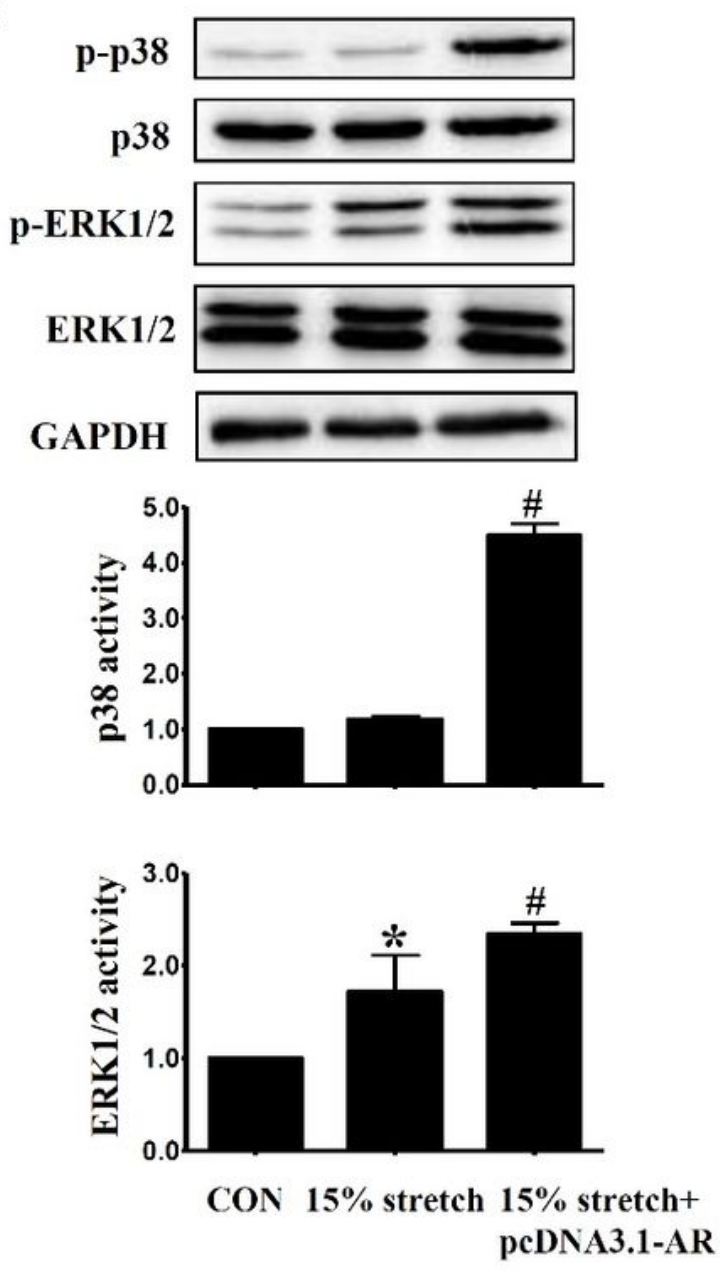

Figure 5

AR realizes the pro-proliferation of $15 \%$ stretch via activations of $p 38$ and ERK1/2. (A) Myoblasts C2C12 (with AR) and L6 (no detectable AR) were seeded onto flexible-bottomed 6-well plates and incubated for $24 \mathrm{~h}$ prior to $15 \%$ stretch. Then cells were collected and the activities of PI3K/Akt, p38 and ERK1/2 
(reflected as the ratios of p-PI3K/PI3K, p-Akt/Akt, p-p38/p38 and p-ERK1/2/ERK1/2, respectively) were detected by Western blot at $24 \mathrm{~h}$ after stretch finished. The promoted degrees in the activities of PI3K and MAPKs (p38 and ERK1/2) were calculated by the following formula: = (the activities of PI3K/Akt and MAPKs (p38 and ERK1/2) 15\% stretch - the activities of PI3K/Akt and MAPKs (p38 and ERK1/2) CON)/ the activities of PI3K/Akt and MAPKs (p38 and ERK1/2) CON. * indicated $p<0.05$ vs. C2C12 cells. (B) and (C) L6 myoblasts were seeded onto flexible-bottomed 6-well plates one day before transfection, and 2.5

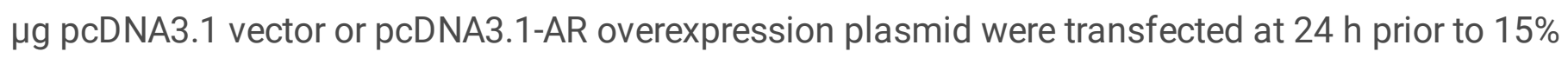
stretch, then the activities of PI3K/Akt, p38 and ERK1/2 were detected by Western blot at $24 \mathrm{~h}$ after stretch finished. ${ }^{*} p<0.05$ vs. CONpcDNA3.1; $\# p<0.05$ vs $15 \%$ stretchpcDNA3.1. The differential values resulting from three independent experiments were compared (mean $\pm S D, n=3$ ). 

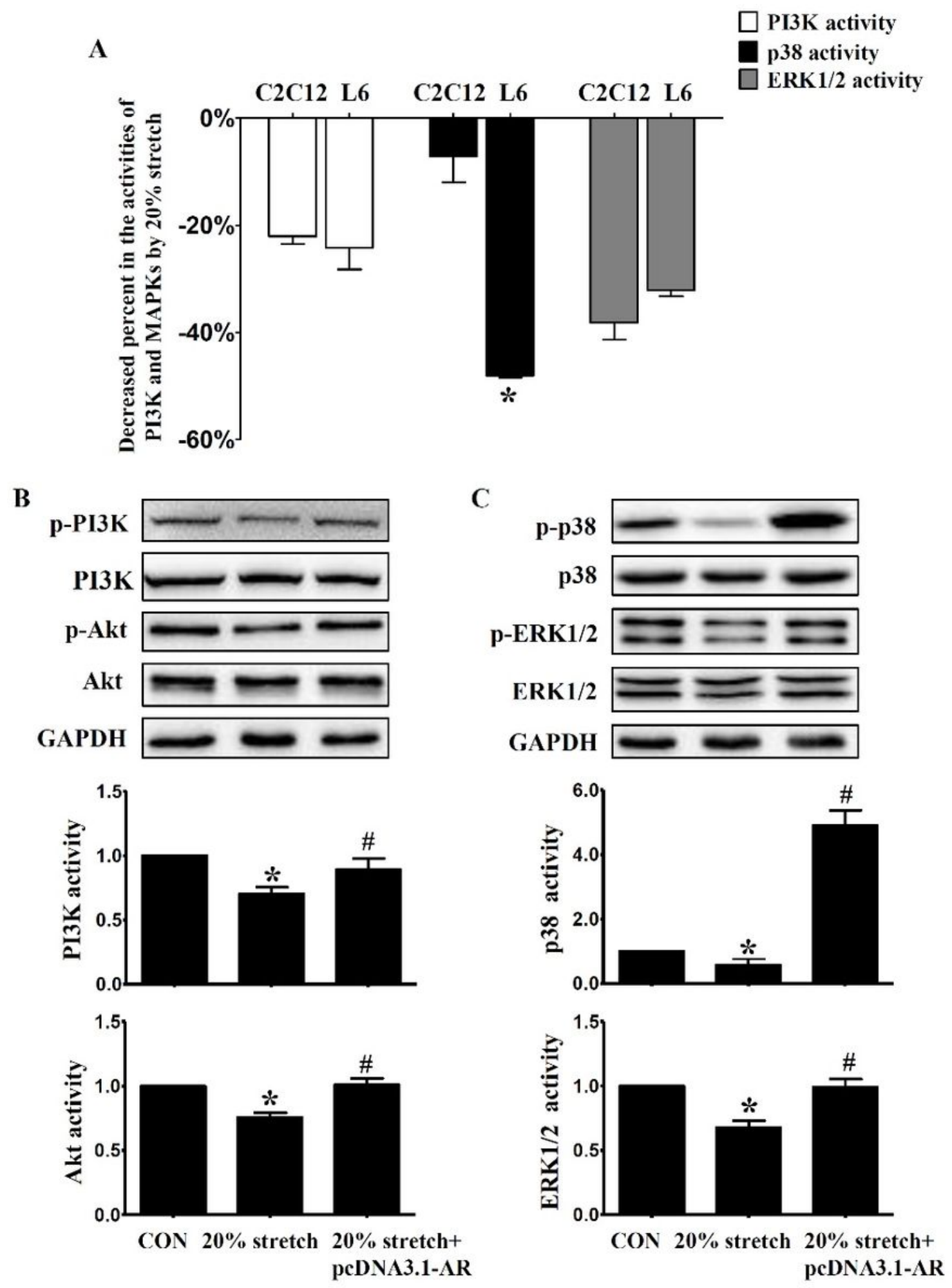

Figure 6

Effects of decreased AR on $20 \%$ stretch-induced anti-proliferation is mediated by inhibiting p38. (A) C2C12 and L6 cells were seeded onto flexible-bottomed 6-well plates at $1 \times 105 / \mathrm{ml}$ density at the same time and incubated for $24 \mathrm{~h}$ prior to $20 \%$ stretch. Then cells were collected and the activities of PI3K/Akt, p38 and ERK1/2 (reflected as the ratios of p-PI3K/PI3K, p-Akt/Akt, p-p38/p38 and p-ERK1/2/ERK1/2, respectively) were detected by Western blot at $24 \mathrm{~h}$ after stretch finished. The decreased extents in 
activities of PI3K, p38 and ERK1/2 were calculated using the following formula: = (the activities of PI3K/Akt and MAPKs (p38 and ERK1/2) 20\% stretch - the activities of PI3K/Akt and MAPKs (p38 and ERK1/2) CON)/ the activities of PI3K/Akt and MAPKs (p38 and ERK1/2) CON. * indicated $p<0.05$ vs. C2C12 cells. (B) and (C) L6 myoblasts were seeded onto flexible-bottomed 6-well plates one day before transfection, when the confluence reached $₫ 50 \%$, pcDNA3.1 vector or pcDNA3.1-AR overexpression plasmid was transfected into L6 myoblasts, then L6 cells were undertaken to $20 \%$ stretch at $24 \mathrm{~h}$ after transfection finished, and the activities of PI3K/Akt, p38 and ERK1/2 were detected by Western blot at 24 h after stretch. ${ }^{*} p<0.05$ vs. CON; $\# p<0.05$ vs $20 \%$ stretchpcDNA3.1.

A
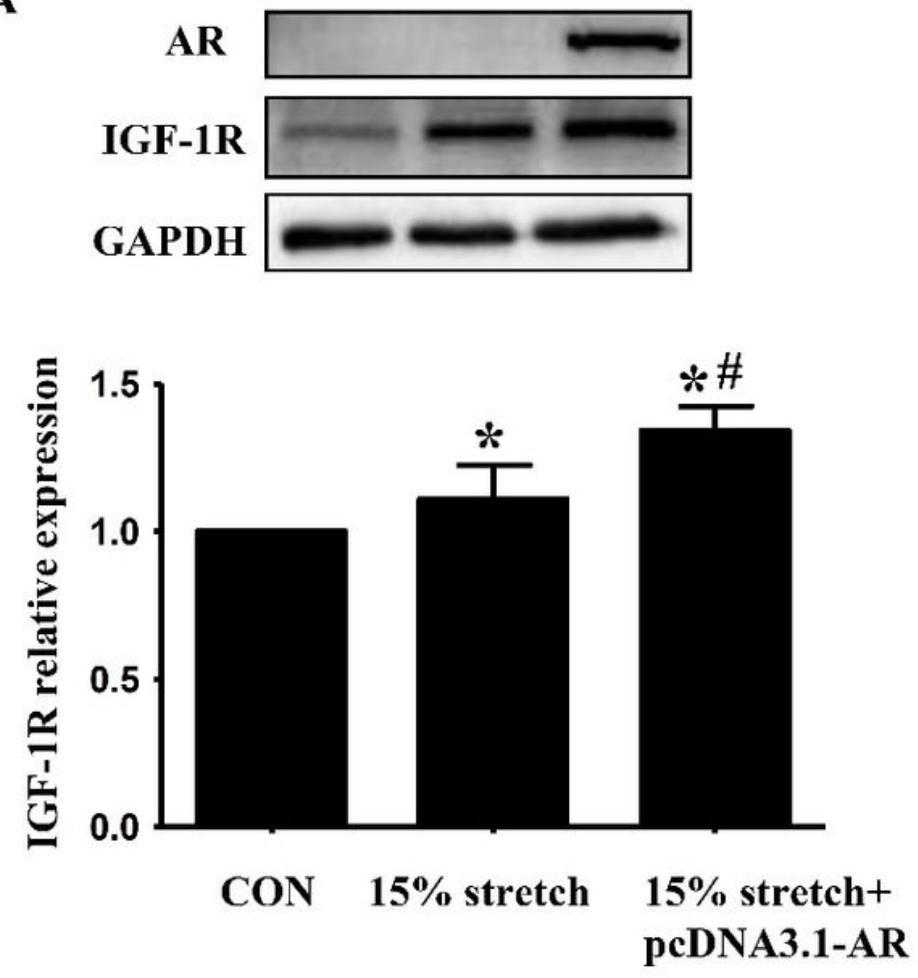

B
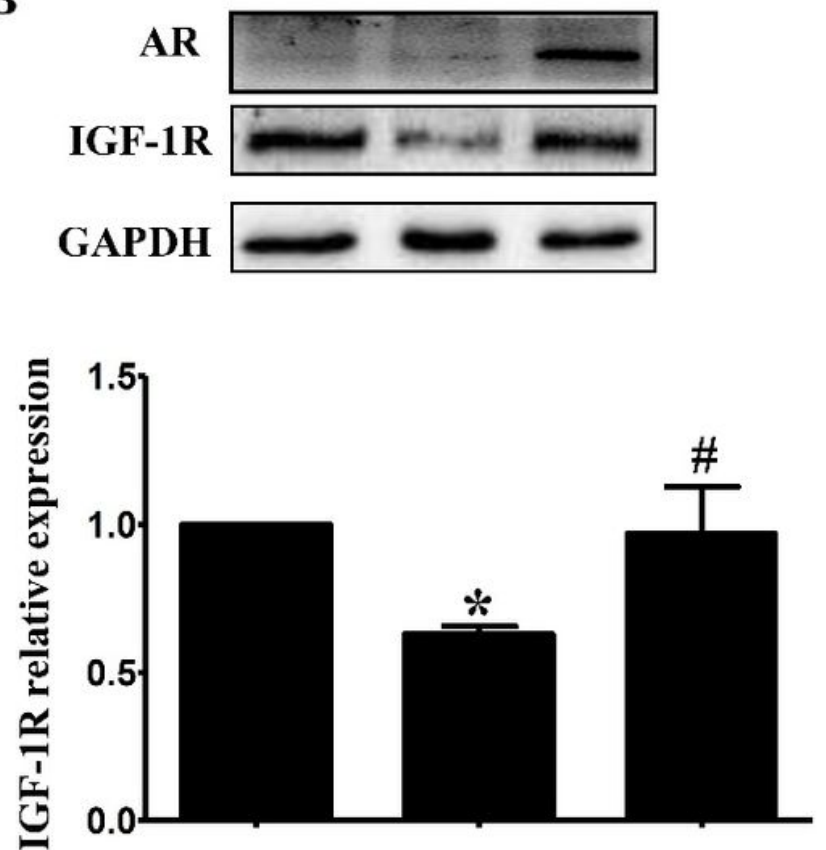

CON $\quad 20 \%$ stretch $20 \%$ stretch+ pcDNA3.1-AR

Figure 7

AR overexpression up-regulates the levels of IGF-1R in L6 myoblasts undertaken $15 \%$ or $20 \%$ stretch. L6 myoblasts were seeded onto flexible-bottomed 6-well plates, and pcDNA3.1-AR overexpression plasmid was transfected when the cell confluence reached $₫ 50 \%$. At $24 \mathrm{~h}$ after transfection, cells were subjected to $15 \%$ or $20 \%$ stretch, then the cells were collected at $24 \mathrm{~h}$ after stretch finished to determine the protein levels of IGF-1R. The results resulting from three independent experiments were analyzed and represented as mean $\pm S D$. ${ }^{*} p<0.05$ vs. CON and $\# p<0.05$ vs $15 \%$ stretch or $20 \%$ stretch. 
A

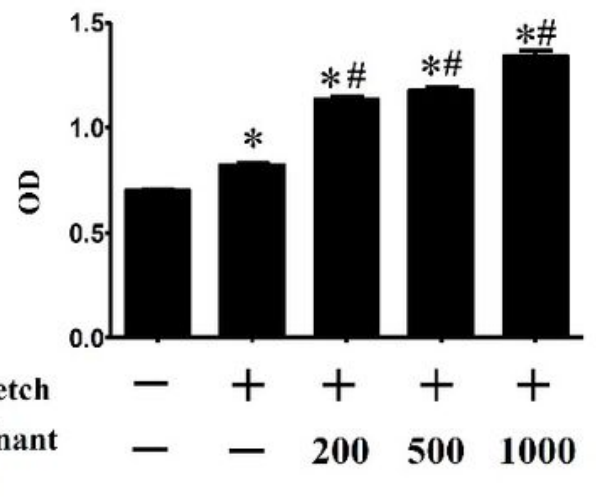

IGF-1 recombinant $\quad-\quad-\quad 200 \quad 500 \quad 1000$ peptide(ng/ml)

C
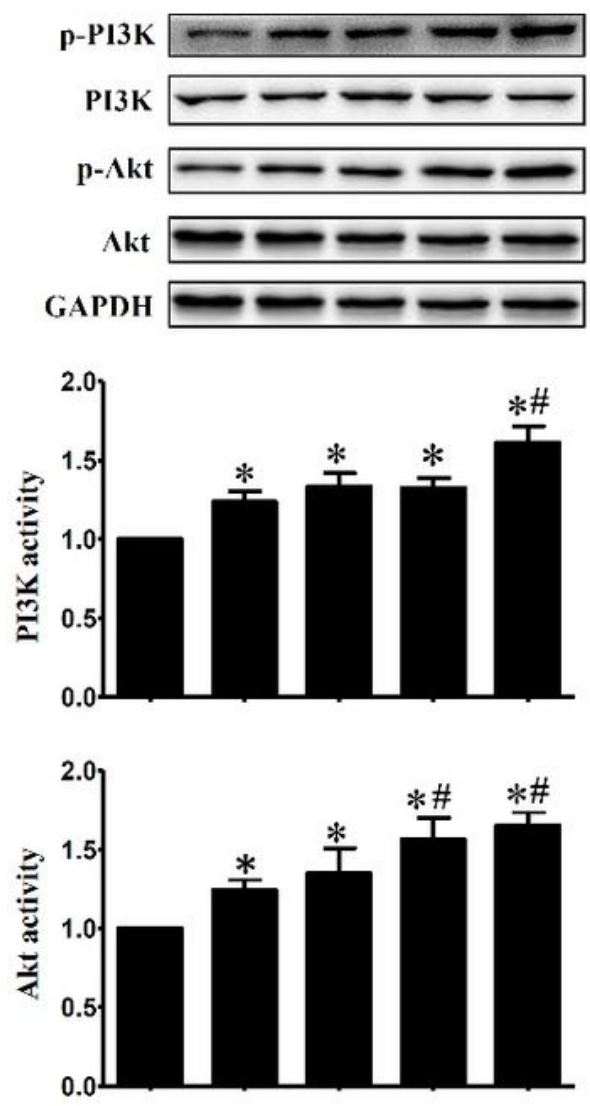

$15 \%$ stretch -++++

IGF-1 recombinant $\quad-\quad-\quad 200 \quad 500 \quad 1000$ peptide $(\mathrm{ng} / \mathrm{ml})$
B
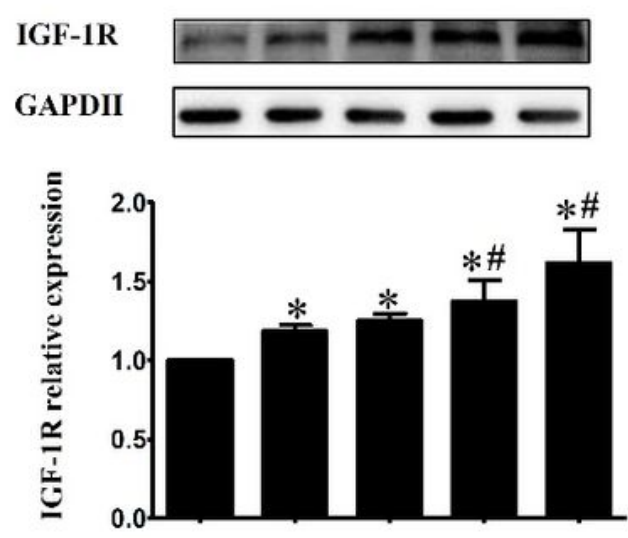

$15 \%$ stretch -++++

$\begin{array}{llllll}\text { IGF-1 recombinant } & - & - & 200 & 500 & 1000\end{array}$ peptide(ng/ml)

D
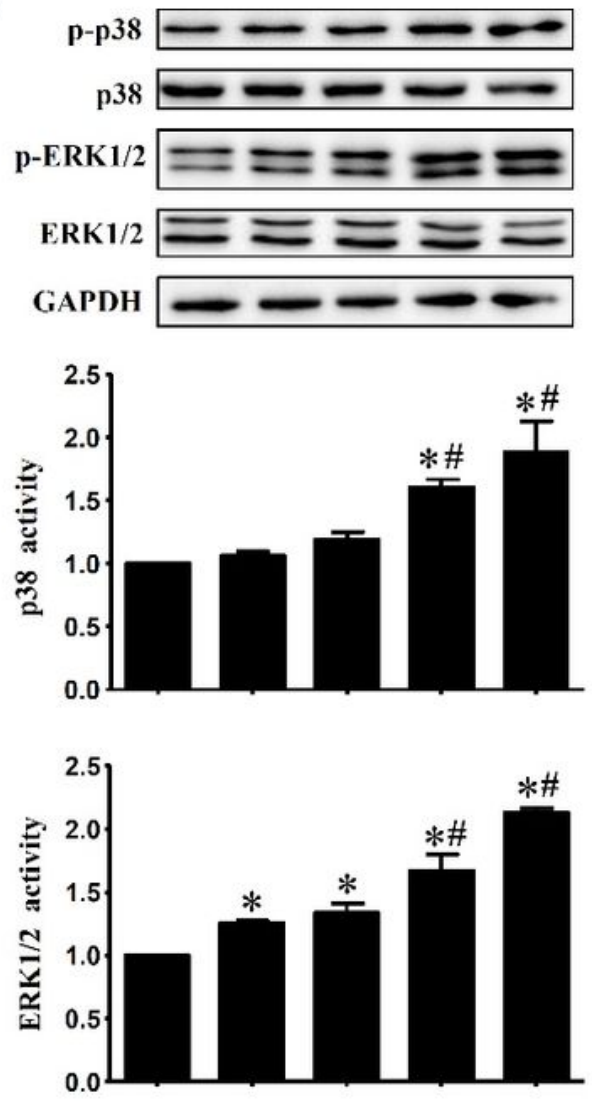

$15 \%$ stretch

$-++++$

IGF-1 recombinant $\quad-\quad-\quad 200 \quad 500 \quad 1000$

\section{Figure 8}

Exogenous IGF-1 enhances the proliferation of 15\%-stretched L6 myoblasts via activating PI3K/Akt, p38 and ERK1/2. IGF-1 recombinant polypeptide at different concentrations $(200,500$, and $1000 \mathrm{ng} / \mathrm{ml})$ were added into L6 cell culture medium at $1 \mathrm{~h}$ prior to $15 \%$ stretch, and cell proliferation were detected by CCK 8 (A); the protein level of IGF-1R (B), and the activities of PI3K/Akt (C) and MAPKs (D) were detected by 
Western blot at $24 \mathrm{~h}$ after stretch finished. The results were from three independent experiments, and the data were analyzed and represented as mean \pm SD. ${ }^{*} p<0.05$ vs. CON; \#p<0.05 vs $15 \%$ stretch. 